\title{
Servitization of Manufacturer and Intellectual Property Protection_Empirical Analysis Based on the OECD Countries
}

\author{
Zhibin Zhang \\ Economic Department, Shanghai University, Shanghai, China
}

\section{Email address:}

1054026964@qq.com

\section{To cite this article:}

Zhibin Zhang. Servitization of Manufacturer and Intellectual Property Protection_—Empirical Analysis Based on the OECD Countries. Science Innovation. Vol. 4, No. 6, 2016, pp. 278-282. doi: 10.11648/j.si.20160406.16

Received: November 4, 2016; Accepted: November 30, 2016; Published: December 7, 2016

\begin{abstract}
In this paper, through using the OECD (Organization for Economic Co-operation and Development) data and comparing with Chinese data, the result shows that the overall, labor-intensive, capital-intensive and technology-intensive manufacure of China all have low servitization degree, which results the Chinese manufature stays in the low stage of the global value chain. At the same time, the empirical analysis on the level of intellectual property protection and the servitization of manufacture shows that the improvement of intellectual property protection can contribute to the integration of manufacturing and service, and this role in technology-intensive manufacturing is more obvious. This study also finds that the proportion of employment in service sector, the competitiveness of manufacture will positively promote the overall and different factors intensive manufacturing servitization degrees, while the level of innovation and economic freedom will inhibit the servitization of manufacture.
\end{abstract}

Keywords: Servitization, Intellectual Property Protection, Input-Output

\section{制造业服务化与知识产权保护一一基于 $0 \mathrm{ECD}$ 国家研究}

张志涁

经济学院, 上海大学, 上海, 中国

邮箱

1054026964@qq.com

摘要：本文通过对OECD（经济合作与发展组织）国家2007-2011年投入产出表数据与中国数据对比分析发现中国整体、 劳动、资本以及技术密集型制造业服务化系数均较低, 导致中国制造业竞争力较弱。同时对知识产权保护水平与制造 业服务化进行实证分析, 发现, 知识产权保护水平的提升能有助于制造业与服务业的融合, 且这种促进作用在技术密 集型造制业中表现更明显。同时, 研究发现服务业就业比重、各制造业竞争力对于整体和各类制造业的服务化水平也 有正向影响，而创新水平和经济自由度反而会对制造业服务化产生抑制作用。

关键词：制造业服务化, 知识产权保护, 投入产出 


\section{1. 引言}

目前, 全球服务业占世界经济的比重已经超过 $70 \%$, 主 要发达国家的服务业甚至达到 $80 \%$, 而服务贸易额也已经超 过世界贸易总额的 $1 / 4$, 进入后工业时代的发达国家正引导 着世界经济向服务经济聚集。反观中国，2013年中国第三 产业增加值比重已经达到 $46.9 \%$, 并于 2012 年首次超越第二 产业比重, 但是对比发达国家仍有不小的差距。黄莉芳和 杨向阳 [1]认为相对于发达经济体, 中国服务业存在着总量 和结构性滞后、增长速度缓慢及发展效率低下等突出矛盾, 中国服务业整体上正经历缓慢的粗放式增长，对国民经济 增长的贡献率和产业关联效应均不容乐观。

随着全球服务业的迅速发展, 服务业与制造业的融合 也越来越频繁, 服务业因其柔性生产的特点渐渐成为制造 业的良性 “润滑剂”。放眼世界, 全球制造业正在向服务 业进行转型, 越来越多的发达国家跨国制造企业服务化程 度逐步上升。比如美国的IBM、日本的丰田、英国的罗尔 斯-罗伊斯, 不再将生产的重点局限在实物产品的生产, 而是更加关注产品价值的实现，提供 “产品+服务”、“购 买+体验” 的理念。而中国作为全球最大的制造业基地, 制造业的国际竞争力和附加值率却与发达国家存在不小 的差距。借鉴发达国家经验，提升制造业服务化程度是提 升中国制造业竞争力以及全球价值链地位的重要途径。

这种制造业与服务业融合的过程是产业结构软化在 制造业的表现形式 [2], 而这种产业结构的软化也逐渐成 为当今知识经济时代新的产业革命和产业转型的表现形 式。而随着知识经济作为一种新的经济形态日益取得重要 地位, 世界各国知识产权保护标准的制定也成为知识经济 背景下新的议题。因此在制造业服务化与知识产权保护水 平之间是否存在着一定的相关性便成为本文研究的重点。 本文利用国际投入产出表，对比分析具有典型代表性的 OECD (经济合作与发展组织) 国家的生产性服务与制造业 融合程度及其影响因素, 为推动中国制造业服务化, 促进 产业升级转型提供借鉴。

\section{2. 文献综述}

首先提出制造业服务化概念的是 Vandermerwe 和 Rada [3]，他们提出制造业服务化是指制造业中服务份额 占比的增加为产品带来的价值增加, 实质是生产性服务业 向制造业价值渗透融合的过程。最近, Baines [4] 又将制 造业服务化定义为: 从销售实物产品到销售产品加传递产 品使用价值的服务的创新过程。

\section{1. 国外研究}

随着制造业服务化概念的提出, 国外学者纷纷展开对 各国制造业服务化的研究。Neely [5]利用全球上市公司分 析库 (OSIRIS) 中 23 个不同国家的 10, 078家企业数据进行 分析，发现不同国家制造业服务化程度不同，其中美国最 高, 中国最低。Neely [6]对上述企业数据进一步分析发现, 企业销售收入以及企业大小都是影响制造业企业服务化 的重要因素。Falk和Peng[7]发现欧洲制造业与服务业融
合程度在近几十年越来越明显, 二者界限已经越来越模糊。 并通过对欧洲18国制造业部门1995-2008年的制造业服务 化程度进行分析, 发现服务业就业比重对制造业服务化有 显著正向影响, 服务从业人员中的管理人员、技术人员比 例对制造业服务化程度显著正相关。Arnold等 [8]对印度 制造业部门数据进行研究发现, 金融、交通运输以及通讯 服务是印度制造业的重要投入, 而且随着服务业的改革, 制造业中投入的服务越多，制造业的生产效率也会越高。

\section{2. 国内研究}

在国内研究中, 刘继国和赵一婷 $[9]$ 通过测度 9 个 $0 E C D$ 国家从 20 世纪70年代到 90 年代制造业对服务业依赖程度的 变化, 证实了世界范围内制造业和服务业融合的趋势。二 者 [10]还基于问卷调查数据对制造业产出服务化的影响因 素进行实证分析, 发现, 环境因素、组织因素、顾客因素 等对制造企业服务化产出具有重要影响。周艳春 [11]则利 于中国上市公司数据找到四个影响制造企业业服务化的因 素: 环境动态性、员工素质、品牌因素、企业规模。赵勇 等 [12]认为制造企业服务化驱动力来自内外两方面, 内部 驱动力主要是服务部门人员, 而外部主要有市场环境、顾 客需求。黄慧群和霍景东 [13]则从宏观角度出发, 利用 1995-2009年主要制造业国家的投入产出数据, 对影响制造 业服务化程度的因素进行实证分析, 发现创新能力、经济 自由度和人力资本水平对制造业服务化有显著推动作用; 而制造业附加值率、制造业投入服务化强度对制造业服务 化有一定抑制作用。綦良群 [14]从中国装备制造业出发归 纳出影响制造业服务化的环境因素和组织因素包括资源约 束、产业竞争强度、服务经济水平以及政府政策等。宁进 [15]则通过针对中国装备制造业的研究发现, 产业竞争环 境、技术水平以及组织专业化分工等因素会共同影响装备 制造业服务化水平。

国内外研究表明, 无论是发达国家还是发展中国家, 制造业与服务业融合程度都在不断加深, 而影响制造业服 务化的因素也是多种多样。但是分析大多集中在对微观企 业的分析上, 缺少整体性和宏观性的研究。而有关制造业 服务化与知识产权保护水平之间关系的研究仍未出现, 而 且目前关于知识产权保护的研究也都大多停留在对经济 增长、贸易量以及创新水平的研究上, 并未出现对于有关 产业结构的研究。因此, 本位将在黄慧群和霍景东的思路 基础上, 研究制造业服务化与知识产权保护水平之间的关 系。同时，由于周大鹏［16] 曾指出服务要素投入对不同类 型制造业升级的影响程度是不同的, 因此本文还将对不同 要素密集度的制造业进行分开讨论。

\section{3. 文章结构安排}

本文将对 27 个 $0 \mathrm{ECD}$ 国家的投入产出数据进行对比分 析, 并对知识产权保护是如何影响整体制造业及不同要素 密集度制造业的服务化程度进行实证分析。本文以下的结 构安排: 第三部分是各国制造业服务化程度对比; 第四部 分是模型设定和数据说明; 第五部分是回归结果和分析; 第六部分是结论与启示。 


\section{3. 各国制造业服务化程度对比}

本文选取 27 个具有代表性的 OECD国家 (澳大利亚、奥 地利、比利时、加拿大、捷克、德国、丹麦、西班牙、爱
沙尼亚、芬兰、法国、英国、希腊、匈牙利、爱尔兰、意 大利、日本、韩国、卢森堡、墨西哥、荷兰、波兰、葡萄 牙、斯洛伐克、斯洛文尼亚、瑞典、美国) 作为比较对象,

表1 按照要素密集度划分制造业。

\begin{tabular}{lll}
\hline 类别 & 行业个数 & 包含行业 \\
\hline 劳动密集型 & 6 & 食品饮料烟草制造业、纺织业、皮革制品制鞋业、木材加工制造业、造纸和纸制品业、橡胶和塑料制品业 \\
资本密集型 & 5 & 石油加工、炼焦和核燃料加工业、非金属矿物制品业、金属制品业、机械制造业、交通运输设备制造业 \\
技术密集型 & 3 & 化学原料和化学制品制造业、电气光学仪器制造业、废弃资源综合利用业 \\
\hline
\end{tabular}

注: 结合牀秀峰和韩亚峰[17]分类标准和国际投入产出表

利用各国历年投入产出表数据继续分析, 并将各制造 业根据要素密集度进行分类一一劳动密集型制造业、资本 密集型制造业、技术密集型制造业。(分类标准参照表1) 通过构建制造业服务化指数来衡量制造业服务化强度。

制造业服务化系数表示为:

$$
S I I_{i}=\frac{\sum s_{i}^{j}}{\sum Y_{i}}
$$

其中, $\mathrm{S}_{\mathrm{i}}^{\mathrm{j}}$ 表示 $\mathrm{i}$ 要素密集型制造业中投入的服务产品 $\mathrm{j}$ 的数量。 $\mathrm{j}$ 表示生产性服务, 根据国际投入产出表行业分 类包括: 批发零售服务、住宿餐饮服务、交通运输服务、 金融保险服务、不动产活动、租赁及其他商务服务。 $\mathrm{Y}_{\mathrm{i}}$ 表 示i要素密集型制造业的总产出。

表2 部分 $0 \mathrm{ECD}$ 国家制造业服务化水平对比(单位: \%)。

\begin{tabular}{llllll}
\hline 国家 & 2007 & 2008 & 2009 & 2010 & 2011 \\
\hline 德国 & 22.35 & 22.96 & 24.71 & 23.63 & 22.40 \\
丹麦 & 24.35 & 24.90 & 25.82 & 25.58 & 26.81 \\
法国 & 27.50 & 28.00 & 29.22 & 29.13 & 28.86 \\
英国 & 23.93 & 24.56 & 25.00 & 24.10 & 23.65 \\
日本 & 16.30 & 16.70 & 17.23 & 16.42 & 16.00 \\
美国 & 20.10 & 19.14 & 19.96 & 19.34 & 19.00 \\
墨西哥 & 15.45 & 15.51 & 16.52 & 16.05 & 15.55 \\
中国 & 9.94 & 10.19 & 10.78 & 10.52 & 10.48 \\
\hline
\end{tabular}

注: 数据由投入产出表计算得出

表2 显示部分OECD国家整体制造业的服务化程度的变 化趋势。总体来看, OECD国家整体制造业的服务化水平均 较高, 大多数都在 $20 \%$ 以上, 甚至部分国家多年在 $25 \%$ 以上, 达到相当高的水平。而反观中国, 虽然呈现出逐年上升的 趋势, 但是水平依旧处于较低的水平, 对比同为发展中国 家的墨西哥, 中国仍旧是落后的, 这也充分说明作为制造 业大国的中国离制造业强国还有一定距离。再看各国发展 趋势, 不难注意到高度发达国家的制造业服务化水平近年 来呈现下滑趋势, 这与这些国家制造业附加值率较高会掉 入 “服务陷阱” [6]有关, 也就是说, 制造业的高附加值 率虽然会为制造业服务化提供一定的基础，但也会抑制制 造业服务化的动力。

\section{4. 模型设定和数据说明}

本文着重研究制造业服务化与知识产权保护水平之 间关系，因此模型设定为:

$$
S I M_{i, k, t}=\alpha_{0}+\alpha_{1} \operatorname{lnippi}_{k, t}+\alpha_{2} X_{k, t}+\varepsilon_{k, t}
$$

$X_{k, t}$ 为控制变量, 结合制造业服务化特点和相关研究, 可以找出影响制造业服务化系数的因素。Markusen[18] 认为制造业成品中服务投入数量与工资水平正相关而与 产品价格负相关。Falk和Peng [7]则通过对比欧洲制造业 服务化程度发现服务业就业人口对其有正向促进作用。黄 慧群和霍景东 [13] 认为交易成本、人力资本水平、国家创 新能力以及制造业附加值率均对制造业服务化有一定影 响。因此, 本文选择已有研究选择将服务业就业比重、整 体制造业和不同要素密集度制造业的竞争力、研发支出占 比和经济自由度四个变量引入模型。

其中, SIM $\mathrm{i}_{\mathrm{i}, \mathrm{k}, \mathrm{t}}$ 表示制造业服务化系数，包括整体、劳动 密集型、资本密集型以及技术密集型制造业情况, 数据通 过各国投入产出表计算获得。ippi $i_{k, t}$ 表示 $k$ 国 $t$ 时期的知识 产权保护水平, 对于该数据, 许多文献使用的是Ginarte 和Park [19]开发的指数, Park [20]把该指数延续到2005年, 但是该指数每五年一个数值, 数据重复性太大, 不利于本 文进行动态分析。本文则借鉴Yang和Huang [21] 的数据采集 方法, 使用WEF（World Economic Forum）的知识产权保护 数据, 该数据是每年连续的问卷调查数据, 符合本文需要; sste表示服务业就业人口占总就业人口的比重, 数据来源 于世界银行数据库; $\mathrm{cm}$ 表示不同国家不同时期的整体及不 同要素密集型制造业的竞争力, 这里通过计算投入产出表 中的行业贸易竞争力指数 $\mathrm{TC}=($ 出口- 进口) / (出口+进口) 而 得; rds 表示的是各国研发支出占GDP比重, 用来衡量国家 创新能力, 数据来源于世界银行数据库; ief表示各国经济 自由度指数, 是用来衡量交易成本的变量, 数据来源于经 济自由度网站 (http://www. freetheworld. com/)。本文对 各变量作出如下预期:

H1：知识产权保护水平越高, 对于知识密集程度更高 的服务创新者, 其权益得到更有效的保障, 从而促进制造 业与服务业更好地融合发展, 提升制造业服务化水平;

H2：服务业就业人员比重越高, 服务更易获取, 制造 业服务化系数越高; 
H3：制造业竞争力越强, 产品价格越低, 制造业成品 中投入的服务产品数量越多, 服务化系数越高; 数越大;

H4: 研发投入越多, 创新能力越强, 制造业服务化系

H5: 交易成本越高, 经济效率的净损失越大, 对制造 企业进行服务化的收益损失也会越大，使其服务化的倾向 降低, 导致制造业服务化系数越低。因此经济自由度越高, 交易成本越低，制造业服务化程度越高。

\section{5. 回归结果和分析}

本文利用上述提及的 27 个 OECD国家2007-2011的数据 进行分析, 分别从整体制造业、劳动密集型制造业、资本 密集型制造业以及技术密集型制造业角度出发, 考察各自 服务化程度与知识产权保护水平这两个变量之间关系进 行研究, 回归方法选取稳健标准误最小二乘估计 (OLS)。 回归结果如表3所示。

根据表 3 的回归结果, 回归方程总体显著, 多数变量 均在 $1 \%$ 的置信水平下显著。

结果表明无论是对整体制造业、劳动密集型制造业、 资本密集型制造业还是技术密集型制造业, 知识产权保护 水平对制造业服务化水平均产生正向促进影响, 且结果都
在 $1 \%$ 的置信水平下显著, 这一结论符合 $\mathrm{H} 1$ 预期。通过对比 系数, 可以发现技术密集型制造业>整体制造业>资本密集 型制造业>劳动密集型制造业, 究其原因, 是因为技术密 集型制造业所含知识要素最多, 因此较好的知识产权保护 水平能更好地保护技术所有者的利益, 从而促进技术密集 型制造业与服务业更好地融合。

再看其他因素, 发现服务业就业比重与制造业服务化 也基本呈现显著性正相关关系, 符合预期 $\mathrm{H} 2$ 。这一结果也 符合Falk和Peng[7]对欧洲制造业服务化研究结果, 说明 服务业就业人口越多, 会从投入数量和成本两方面促进制 造业投入服务要素，从而促进制造业服务化程度提高。研 发支出占比与制造业服务化显著负相关, 说明创新水平越 高, 反而会抑制制造业服务化水平提升，这一结果与预期 $\mathrm{H} 4$ 相悖。原因可能与研发支出结构有关, 倘若研发支出大 部分投入制造业会导致制造业创新水平大幅领先服务业, 这也会弱化制造业实现服务化的趋势，因此后续可以通过 引入研发支出结构变量进行进一步研究。而无论是对整体 制造业还是其他要素密集型制造业来说, 各制造业竞争力 对制造业服务化均有促进作用, 该结果满足预期 H3。这说 明竞争力的提升有助于提升企业在供应链的位置, 从而使 制造企业更加倾向于采取服务化战略。

表3 OLS估计结果。

\begin{tabular}{|c|c|c|c|c|}
\hline 变量 & 整体制造业 & 劳动密集型制造业 & 资本密集型制造业 & 技术密集型制造业 \\
\hline inpi & $20.82 * * *$ & $12.11 * * *$ & $14.24 * * *$ & $29.25 * * *$ \\
\hline 1pp1 & (2.938) & $(2.439)$ & (3. 093) & $(3.688)$ \\
\hline $\operatorname{csct}$ & $0.16 * *$ & $0.25 * * *$ & 0.084 & $0.16 * *$ \\
\hline sste & $(0.063)$ & $(0.052)$ & $(0.062)$ & $(0.076)$ \\
\hline$r d$ & $\begin{array}{l}-3.46 * * * \\
(0.470)\end{array}$ & $\begin{array}{l}-2.80 * * * \\
(0.391)\end{array}$ & $\begin{array}{l}-2.47 * * * \\
(0.547)\end{array}$ & $\begin{array}{l}-2.87 * * * \\
(0.493)\end{array}$ \\
\hline lefi & $\begin{array}{l}-25.29 * * * \\
(7.554)\end{array}$ & $\begin{array}{l}-31.81 * * * \\
(7.367)\end{array}$ & $\begin{array}{c}-15.51 * \\
(8.296)\end{array}$ & $\begin{array}{l}-32.54 * * * \\
(8.547)\end{array}$ \\
\hline $\mathrm{cm}$ & $\begin{array}{l}0.088 * * * \\
(0.021)\end{array}$ & & & \\
\hline clim & & $\begin{array}{l}0.163 * * * \\
(0.018)\end{array}$ & & \\
\hline ccim & & & $\begin{array}{c}0.045 * * \\
(0.028)\end{array}$ & \\
\hline ctim & & & & $\begin{array}{l}0.04 * * \\
(0.0164)\end{array}$ \\
\hline 常数项 & $\begin{array}{c}33.32 * * \\
(12.98)\end{array}$ & $\begin{array}{l}52.42 * * * \\
(13.19)\end{array}$ & $\begin{array}{c}25.89 * \\
(13.30)\end{array}$ & $\begin{array}{c}36.64 * * \\
(14.56)\end{array}$ \\
\hline 样本量 & 135 & 135 & 135 & 135 \\
\hline $\mathrm{R}^{2}$ & 0.536 & 0.695 & 0.261 & 0.551 \\
\hline
\end{tabular}

注: $* * * p<0.01, * * p<0.05, * p<0.1$

\section{6. 结论与启示}

中国虽然作为制造业大国，但是不论是整体制造业、 劳动密集型制造业、资本密集型制造业还是技术密集型制 造业, 服务化程度都与发达国家存在不小的差距, 甚至与 同为发展中国家的其他国家仍存在差距, 这也说明中国距 离成长为制造业强国仍有很长的路要走。从增长趋势来看, 中国经历了世纪初的下滑后, 近年来才开始回升, 但是增 长趋势较平缓, 缺乏增长的动力。
制造业服务化是推动制造业转型升级的关键, 是攀升 全球价值链、增强产业国际竞争力的有效途径。本文通过 对比分析OECD国家知识产权保护水平与制造业服务化程 度之间关系, 发现, 知识产权保护水平的提升能有助于制 造业与服务业的融合, 且这种促进作用在技术密集型制造 业中表现更明显。同时，研究发现服务业就业比重、各制 造业竞争力对于整体和各类制造业的服务化水平也有正 向影响, 而创新水平和经济自由度反而会对制造业服务化 产生抑制作用。 
结合本文结论, 为推动中国制造业实行服务化战略, 提升知识产权保护水平可以作为重要举措。而中国知识产 权保护发展呈现出执法水平跟不上立法水平的局面, 立法 水平已基本赶上发达国家，然后执法却严重落后，在知识 产权战略背景下, 这也对执法机构提出了更高的要求。同 时促进服务业就业, 提升制造业竞争力也是促进中国制造 业服务化发展战略的重要措施。

\section{参考文献}

［1］黄莉芳, 杨向阳. 中、美现代服务业内部结构演变趋势比较 -一来自投入产出表的经验证据 $[\mathrm{J}]$. 世界经济研 究, 2015, 3:99-106。

[2] 马云泽. 世界产业结构软化趋势探析 $[J]$. 世界经济研 究, 2004, 6(1) : 15-19。

[3] Vandermerwe. S. and J. Rada. Servitization of Business: Adding Value by Adding Services [J]. European Management Journal, 1989, 6 (4) : 314-324.

[4] Bains T. S., Lightfoot H. W. and Benedettini 0. The servitization of manufacturing: areview of literature and reflection of future challenges [J]. Manufacturing Technology Management, 2009, 20 (5): $547-567$.

[5] Neely Andy. The Servitization of Manufacturing: an Anlsysis of Global Trends [J]. 14th European Operations Management Association, 2007: 1-10.

[6] Neely Andy. Exploring the financial consequences of the servitization of manufacturing $[\mathrm{J}]$. Operations Management Research, 2008, 1 (2) : 103-118.

[7] Falk M. and Peng F.. The increasing service intensity of European manufacturing $[J]$. The Service Industries Journal, 2013, 33 (15-16) : 1686-1706.

[8] Arnold J. M., Javorcik B. and Lipscomb M, et al.. Services reform and manufacturing performance: Evidence from India, The Economic Journal, 2014, 10 (02) : 1-39.
［9］刘继国, 赵一婷. 制造业中间投入服务化趋势分析一一基于 OECD 中 9 个国家的宏观实证 $[\mathrm{J}]$. 经济与管 理, 2006, 20 (9):9-12。

[10] 刘继国, 赵一婷. 制造业企业产出服务化战略的影响因素及 其绩效: 理论框架与实证研究 $[\mathrm{J}]$. 上海管理科 学, 2008, (6) :42-46。

[11] 周艳春. 制造企业服务化战略实施及其对绩效的影响研究 [D]. 西北大学, 2010。

[12] 赵勇, 齐讴歌, 曹林. 装备制造业服务化过程及其保障因素 - - 基于陕鼓集团的案例研究 $[J]$. 科学学与科学技术管 理, 2012, 33 (12) : 108-117。

[13] 黄群慧, 霍景东. 全球制造业服务化水平及其影响因素一一 基于国际投入产出数据的实证分析 $[\mathrm{J}]$. 经济管 理, 2014(1):1-11。

[14] 綦良群, 赵少华, 蔡渊渊. 装备制造业服务化过程及影响因 素研究一一基于我国内地 30 个省市截面数据的实证研究 [J]. 科技进步与对策, 2014, 31 (14) : 47-53。

[15] 宁进. 中国装备制造业服务化转型的路径因子及其绩效实 证 $[J]$. 求索, 2015(5) : 101-105。

[16] 周大鹏. 制造业服务化对产业转型升级的影响 [J]. 世界经 济研究, 2013, 9:17-22。

［17］䐆秀峰、韩亚峰, 2012: 《生产性服务贸易对制造业生产 效率影响的实证研究——基于价值链视角》, 《国际经贸 探索》第5期。

[18] Markusen J. R. . Trade in producer services and in other specialized intermediate inputs $[\mathrm{J}]$. The American Economic Review, 1989: 85-95.

[19] Ginarte J C, Park W G. Determinants of patent rights: A cross-national study[J]. Research policy, 1997, 26 (3) : 283-301.

[20] Park W G. International patent protection: $1960-2005$ [J]. Research policy, 2008, 37 (4) : 761-766.

[21] Weng Y, Yang C H, Huang Y J. Intellectual property rights and US information goods exports: the role of imitation threat $[\mathrm{J}]$. Journal of Cultural Economics, 2009, 33 (2) : 109-134. 